\title{
As Conseqüências Políticas e Econômicas das Crises entre Executivo e Legislativo ${ }^{\prime}$
}

\author{
Anibal S. Pérez-Liñán \\ Universidade de Pittsburgh
}

\begin{abstract}
Resumo
Boa parte das análises recentes do presidencialismo baseiam-se no pressuposto de que o confronto entre executivo e legislativo cria condições simultâneas para a estabilidade das políticas e para o rompimento do regime. Neste trabalho, mostro que há uma tensão lógica inerente entre essas duas predições e que elas se baseiam em pressupostos contraditórios. Em seguida, desenvolvo um modelo de impasse executivo-legislativo e sustento que a instabilidade do regime é mais provável quando atores partidários são unilateralmente impacientes, quando o desenho institucional é inclinado a favor de um partido e quando o número de partidos é maior. Na terceira seção, testo as predições do modelo usando dados de cortes transversais em séries no tempo para dezenove países do hemisfério ocidental entre 1950 e 2000. Por fim, discuto como essa abordagem ilumina alguns enigmas empíricos, como a sobrevivência histórica do presidencialismo americano e os baixos níveis de instabilidade do regime criados por impasses executivo-legislativo na América Latina na década de 1990.
\end{abstract}

Palavras-chave: presidencialismo, estabilidade, regime, América Latina.

\begin{abstract}
Much of the recent analysis of presidentialism has been based on the assumption that executivelegislative confrontation creates simultaneous conditions for policy stability and regime breakdown. In the first section of the paper, I show that there is an inherent logical tension between these two predictions and that they rely on contradictory assumptions. In the second section, I develop a model of executivelegislative deadlock and argue that regime instability is more likely when partisan players are unilaterally impatient, when institutional design is biased in favor of one party, and when the number of parties is greater. In the third section, I test the predictions of the model using time-series cross-section data for 19 presidential countries in the Western Hemisphere between 1950 and 2000. Finally, I discuss how this approach illuminates some empirical puzzles like the historical survival of American presidentialism and the lower levels of regime instability created by executive-legislative deadlock in Latin America in the 1990s.
\end{abstract}

Keywords: presidentialism, stability, regime, Latin America.

\footnotetext{
${ }^{1}$ Agradeço a Kent Eaton, Jonathan Hartlyn, Scott Mainwaring e Sebastian Saiegh aos comentários feitos à versão preliminar deste artigo.
} 
Nos últimos quinze anos, grande parte das análises comparativas das relações executivo-legislativo nos regimes presidencialistas baseou-se no pressuposto de que o confronto entre dois poderes eleitos de governo gera dois efeitos opostos: estabilidade das políticas e instabilidade do regime. Na primeira parte deste artigo, faço uma revisão desses argumentos e sustento que as expectativas simultâneas de estabilidade das políticas e instabilidade do regime geram um paradoxo analítico. O único modo de resolver esse paradoxo é discriminando situações em que preferências em relação a políticas públicas sejam independentes de preferências quanto a instituições. O argumento dos perigos do presidencialismo supõe que, entre os atores com poder de veto, as preferências por políticas impulsionam as preferências quanto a tipos de regime, enquanto o argumento da estabilidade das políticas toma por suposto que as instituições são exógenas e fixas.

$\mathrm{Na}$ segunda seção, desenvolvo um modelo simples de impasse executivolegislativo que sugere que as disputas em relação a políticas provavelmente predominam sobre o "status quo" institucional quando atores partidários com poder de veto são unilateralmente impacientes, quando o desenho institucional tende a favor de um grupo e quando o número de atores partidários é maior. Uma análise empírica de dezenove países ao longo de 51 anos sustenta essas hipóteses na terceira parte do artigo. As conclusões discutem como essa abordagem nos ajuda a compreender o que parecem ser anomalias na literatura existente sobre presidencialismo.

\section{Conseqüências do impasse executivo-legislativo}

Instabilidade do regime

No final dos anos 80, os estudiosos do presidencialismo chegaram à conclusão de que os sistemas presidencialistas eram mais propensos à ruptura democrática do que os parlamentaristas, pois estes possuem mecanismos destinados a garantir a unidade de propósito entre o executivo e a assembléia como a dissolução do parlamento ou o voto de desconfiança - enquanto os primeiros não costumam tê-los. Na formulação clássica de Juan Linz:

"Uma vez que ambos [o presidente e o congresso] derivam seu poder do voto do povo (...), um conflito está sempre latente e, às vezes, é provável que irrompa de forma dramática; não há um princípio democrático para resolvê-lo e os mecanismos que possam existir na constituição são geralmente complexos, muito técnicos, cheios de 
tecnicalidades legais e, portanto, de legitimidade democrática duvidosa para o eleitorado. Portanto, não é por acidente que em algumas dessas situações, os militares intervenham como poder moderador" (LINZ, 1994, p. 7).

Numa linha semelhante, Riggs (1988) sustentou que

"quando surgem tensões sérias entre o presidente e o congresso nos países que seguem o modelo americano, o constitucionalismo costuma sair perdendo. (...) Embora os movimentos revolucionários populares não sejam incomuns, é muito mais freqüente que pequenos grupos de conspiradores burocráticos, liderados por alguns oficiais militares, dêem um golpe de estado, suspendam o congresso, deponham o presidente e estabeleçam novos governos (inconstitucionais)" (RIGGS, 1988, p. 256).

Na análise que fez do golpe chileno de 1973, Arturo Valenzuela concluiu que

"os desafios da democracia no Chile estavam intimamente
ligados às dificuldades de tornar compatível uma estrutura
constitucional presidencialista (...) e um sistema político multipartidário
polarizado no qual nenhum partido (ou tendência política de direita,
centro ou esquerda) conseguia uma maioria para eleger o presidente ou
apoiá-lo no legislativo" (VALENZUELA, 1994, p. 93).

Nos anos 90, ao mesmo tempo em que boa parte da literatura qualificava ou revisava o argumento de Linz, o pressuposto básico permanecia inalterado. Os estudiosos procuraram estabelecer as condições para o impasse executivolegislativo sem questionar a lógica subjacente do argumento (para uma exceção, ver CHEIBUB, 2002). Em um artigo clássico, Scott Mainwaring sustentou que é, de fato, a interação entre presidencialismo e multipartidarismo que constitui uma "combinação difícil" para a democracia, pois: 1) "o multipartidarismo aumenta a probabilidade de impasse executivo-legislativo"; 2) "ele aumenta também a probabilidade de polarização ideológica"; e 3) torna a montagem de coalizões "mais difícil e menos estável do que nos sistemas parlamentaristas" (MAINWARING, 1993, pp. 212-13). Enfatizando o papel dos sistemas eleitorais na criação de formas viáveis de presidencialismo, Mark Jones assinalou também que 
"se o objetivo de um sistema presidencialista é proporcionar uma forma democrática efetiva e estável de governo que sobreviva por mais de umas poucas eleições, então o sistema deve, via de regra, propiciar ao presidente uma maioria ou quase maioria legislativa" (JONES, 1995, p. 160).

Przeworski e seus colaboradores verificaram que as democracias presidencialistas são menos duráveis do que as parlamentaristas e observaram que "elas parecem particularmente vulneráveis em situações nas quais o maior partido do legislativo controla mais de um terço, mas menos do que a metade dos assentos" (PRZEWORSKI et al, 2000, p. 134-35). Eles tentaram dar duas explicações para isso: impasse executivo-legislativo (o presidente não consegue aprovar suas políticas e o congresso não consegue anular seu veto) e "a dificuldade de formar coalizões legislativas quando há poucos partidos com forças similares"2.

Por sua vez, Shugart e Carey notaram que em países do Terceiro Mundo, os regimes parlamentaristas eram mais propensos à ruptura do que os presidencialistas e sustentaram que "é o equilíbrio dos poderes do presidente e do congresso, mais do que o presidencialismo per se, que dificulta a democratização em muitos países" (SHUGART e CAREY, 1992, p. 37-38). Em sua opinião, é mais provável que presidentes com fortes poderes legislativos entrem em choque com o congresso e estejam menos dispostos a chegar a um acordo. Os dados confirmavam que os sistemas presidencialistas com presidentes poderosos apresentam maior probabilidade de ruptura (SHUGART e CAREY, 1992, capítulo $8)^{3}$. Tsebelis (1995) explicou os resultados de Shugart e Carey afirmando que os poderes presidenciais fortes criam um ator adicional com poder de veto no sistema.

Resumindo essas idéias, Mainwaring e Shugart (1997) afirmaram que os poderes legislativos do presidente e o tamanho e coesão do partido do presidente no congresso eram os fatores institucionais fundamentais com impacto potencial sobre a estabilidade dos regimes presidencialistas:

\footnotetext{
2 Para uma revisão deste argumento, ver Cheibub e Limongi (2002, p. 151): "Quanto ao impasse, o fantasma que supostamente assombra o presidencialismo, ele não é difuso nem está associado à ruptura do regime".

${ }^{3}$ Contra este argumento, Cheibub e Limongi (2002, p. 171-72) observaram recentemente que "uma vez levada em consideração a possibilidade de que o presidente e a maioria [no congresso] têm preferências que se superpõem, então a agenda dos poderes [executivo e] legislativo não precisam implicar paralisia, crise e eventual ruptura".
} 
"Acreditamos que os sistemas presidencialistas tendem a funcionar melhor com limitados poderes executivos sobre a legislação, principalmente porque um executivo mais fraco significa que o congresso tem mais oportunidades de debater e negociar questões controvertidas. Poderes executivos mais fracos significam também que os casos em que o presidente não possui maiorias confiáveis têm menos probabilidade de serem assolados por crises, uma vez que o presidente tem menos instrumentos para tentar driblar o congresso. Por fim, destacamos que o presidencialismo costuma funcionar melhor quando os presidentes têm pelo menos um bloco razoavelmente grande de assentos confiáveis no legislativo" (MAINWARING e SHUGART, 1997, p. 436).

Mais recentemente, um bem-documentado estudo de José Antonio Cheibub contestou a conexão entre impasse executivo-legislativo e capacidade de sobrevivência democrática. Após analisar as taxas de risco de 38 democracias presidencialistas entre 1946 e 1996, Cheibub concluiu com surpresa que

“...contrariando todas as expectativas, presidentes minoritários, governos minoritários e impasses não têm efeitos negativos sobre a sobrevivência dos regimes presidencialistas. (...) Enquanto uma em cada 31 democracias presidencialistas morre quando não há impasse, uma em cada 26 morre quando há impasse. Essa diferença não parece justificar o grau de preocupação com o impasse que se expressa amiúde na literatura comparativa sobre presidencialismo" (CHEIBUB, 2002, p. 301).

\section{Estabilidade das políticas}

Por outro lado, a separação de objetivos entre o executivo e o congresso tem sido apresentada como uma fonte de estabilidade das políticas, uma vez que a decretação de quaisquer mudanças do status quo é mais difícil quando o presidente e o legislador mediano têm preferências conflitantes quanto às políticas públicas. Como observou Kent Eaton,

"quando os poderes executivo e legislativo são controlados por partidos diferentes, ambos podem vetar mudanças de iniciativa do outro poder e os desacordos irreconciliáveis sobre políticas entre os poderes não 
podem ser resolvidos institucionalmente por qualquer outro meio que não seja o impeachment" (EATON, 2000, p. 359)4.

A formulação clássica desse argumento corresponde a Tsebelis, que sustentou que "à medida que aumenta o número de atores com veto necessários para movimentar o status quo, o conjunto de políticas que afetam o status quo não aumenta (isto é, a estabilidade das políticas não diminui)" (TSEBELIS, 1995, p. 297). Numa linha semelhante, Cox e McCubbins (2001) distinguiram entre "separação de poderes" e "separação de propósitos", argumentando que a combinação de ambos gera um número maior de possibilidades de veto. Com um número maior de possibilidades de veto, a capacidade de implementar novas políticas (firmeza) declina, enquanto a capacidade de empenhar-se nas políticas existentes (resolubilidade) aumenta, em parte como conseqüência de um impasse ou paralisia entre ramos do poder. "À medida que o número de vetos aumenta, o sistema político se torna mais resoluto e menos decisivo" (COX e MCCUBBINS, 2001, p.27) ${ }^{5}$.

As implicações para as políticas da tese do impasse inspiraram vários corolários (para alguns exemplos, ver Eaton, 2000). Barry Ames mostrou que "a estrutura institucional do Brasil (...) produz inerentemente um grande número de atores com veto. Em conseqüência, seu governo central tem uma dificuldade enorme de produzir políticas inovadoras" (AMES, 2001, p. 12). Trabalho recente em economia do desenvolvimento afirma que

“países com uma grande magnitude de distrito, um grande número de partidos efetivos representados no legislativo e apoio fraco ao partido governante no legislativo tendem a ser associados a níveis mais altos de gastos públicos, maiores déficits fiscais e mais resposta procíclica ao ciclo dos negócios" (STEIN, TALVI e GRISANTI, 1999, p. 128-29; ver também WORLD BANK, 2002, p. 103).

\footnotetext{
4 Embora o conflito executivo-legislativo seja presumivelmente suficiente para criar impasse, a paralisia pode existir por outros motivos que o confronto entre poderes. Ver Binder (1999) e Tsebelis e Money (1997).

5 Cox e McCubbins (2001) não avaliaram diretamente os efeitos paradoxais de uma maior "resolubilidade" na estabilidade do regime; em vez disso, interpretaram os golpes militares como resultado da separação de poderes e propósitos entre líderes militares e civis.
} 


\section{0 paradoxo}

Como podemos reconciliar as expectativas de estabilidade das políticas e instabilidade do regime embutidas na tese do impasse? Examino duas alternativas. A primeira possibilidade é que estabilidade de políticas e do regime são ortogonais e, portanto, os efeitos do conflito executivo-legislativo quanto às políticas não têm relação com seus efeitos sobre o regime. Esse argumento é fácil de ser eliminado. Embora seja possível conceber um regime duradouro que seja "decisivo demais", é difícil acreditar que a consistência nas políticas possa existir na ausência de estabilidade do regime. Afinal, os líderes de golpes bem sucedidos ou movimentos revolucionários devem promover algumas mudanças importantes nas políticas públicas pelo menos em algumas dimensões essenciais, a fim de justificar seus feitos. Devemos concluir que a estabilidade do regime é uma condição necessária (mas não suficiente) para a resolubilidade das políticas ${ }^{6}$. Essa proposição pode ser refeita dizendo-se que a probabilidade de políticas estáveis na ausência de política estável é virtualmente nula:

$$
P\left(S_{P} \mid \sim S_{R}\right)=0
$$

em que $S$ indica estabilidade, $\sim S$ indica ausência de estabilidade e os subscritos $P$ e $\mathrm{R}$ referem-se a resultados de políticas e regime, respectivamente. Em nome da simplicidade, assumo necessidade estrita, mas o leitor deveria pensar a necessidade (ou suficiência) de um modo probabilístico, em vez de determinista (DION, 1998; RAGIN, 2000; SEAWRIGHT, 2002). Nesse caso, a probabilidade de políticas estáveis na ausência de regime estável estaria perto de zero.

O segundo modo, usualmente aceito, de reconciliar as duas previsões da tese do impasse é argumentar que a estabilidade das políticas, na verdade, conduz à instabilidade do regime (CHEIBUB, 2002). Na medida em que tomaram consciência da tensão teórica subjacente entre as duas, os estudiosos a resolveram tratando a última como uma conseqüência natural da primeira.

"Em regimes em que a mudança de governo é impossível (exceto

a intervalos fixos, como nos regimes presidencialistas), o imobilismo das

\footnotetext{
6 É importante distinguir o significado do "status quo" no sentido técnico discutido aqui e no sentido sociológico mais amplo. Sabe-se que alguns golpes acontecem para evitar uma mudança no status quo. Mas isso costuma significar que os conspiradores buscam desfazer, por exemplo, uma mudança política implementada por um presidente de esquerda que sofre oposição de um congresso de maioria direitista. Nesse caso, o motivo do golpe é o fato de que o presidente alterou o status quo político, pondo em risco assim o status quo social. O golpe, portanto, introduz instabilidade política a fim de preservar a ordem social subjacente.
} 
políticas pode levar à substituição da liderança mediante meios extraconstitucionais (instabilidade do regime)" (TSEBELIS, 1995, p. 321-22).

Essa visão convencional sugere que um excesso de resolubilidade das políticas pode ser uma condição suficiente (mas não necessária) para a instabilidade do regime ${ }^{7}$.

Embora essa crença tenha dominado a interpretação da tese do impasse, é difícil aceitá-la sem qualificações. É simplesmente implausível que demasiada consistência das políticas venha a promover a instabilidade do regime em qualquer circunstância. Afinal, como o próprio Tsebelis observou,

"a firmeza na mudança do status quo é boa quando o status quo é indesejável (...) ou quando um choque exógeno perturba um processo desejável. O compromisso com a não-interferência pode ser preferível quando o status quo é desejável (como quando os direitos civis são estabelecidos), ou se um choque exógeno é benéfico" (TSEBELIS, 1995, p. 294-95).

Uma vez que a literatura não estabeleceu as condições específicas que fazem essa hipótese funcionar, adiarei essa questão para a próxima seção. Expresso apenas a sabedoria comum dizendo que a probabilidade de observar um regime presidencialista instável na presença de impasse político deveria ser significativamente maior do que zero (e maior do que a probabilidade de ruptura na ausência de tal impasse). Em termos estritos, a probabilidade de ruptura deverá ser de 1.0 se aceitarmos uma tese determinista de suficiência, ou aproximar-se desse valor se pressupusermos quase-suficiência estocástica. Dadas as condições (desconhecidas) que parecem constranger essa hipótese, fiquemos por enquanto com uma versão mais conservadora ${ }^{8}$.

$$
0 \leq P\left(\sim S_{R} \mid \sim S_{P}\right)<P\left(\sim S_{R} \mid S_{P}\right) \leq 1
$$

Segue-se das proposições [1] e [2] que a tese do impasse envolve uma contradição inerente. Se a excessiva resolubilidade das políticas fomenta a instabilidade do regime, e a estabilidade do regime é potencialmente necessária para a resolubilidade das políticas, devemos concluir que, em equilíbrio, as duas previsões da tese do impasse não são compatíveis. Ou seja, é provável que níveis

\footnotetext{
7 Observe-se que o termo firmeza faz pouco sentido quando aplicado a regimes.

8 Tsebelis (1995, p. 293) expressou a proposição [2] ao argumentar que "elas são inversamente relacionadas: a estabilidade das políticas causa a instabilidade do governo ou do regime".
} 
extremos de impasse executivo-legislativo provoquem uma ruptura do regime, ou imobilismo das políticas, mas é improvável que provoquem ambos no longo prazo.

A prova formal da existência desse paradoxo pode ser obtida com facilidade. A partir da regra de Bayes, sabemos que:

$$
P\left(\sim S_{R} \mid S_{P}\right)=\frac{P\left(\sim S_{R}\right) P\left(S_{P} \mid \sim S_{R}\right)}{P\left(\sim S_{R}\right) P\left(S_{P} \mid \sim S_{R}\right)+P\left(S_{R}\right) P\left(S_{P} \mid S_{R}\right)}
$$

E da proposição [1], por substituição:

$$
P\left(\sim S_{R} \mid S_{P}\right)=\frac{0}{P\left(S_{R}\right) P\left(S_{P} \mid S_{R}\right)}
$$

Portanto, [1] e [2] não podem ser verdadeiras simultaneamente, a não ser que $0<P\left(\sim S_{R} \mid S_{P}\right)=0$.

Como podemos dar conta desse paradoxo? Qualquer tentativa de tratar dessa questão com a introdução de uma distinção entre democracias presidencialistas consolidadas e não-consolidadas - as primeiras presumivelmente diante da estabilidade das políticas e as últimas sujeitas à instabilidade de regime leva simplesmente a uma tautologia. A teoria prevê que institucionalização fraca é o produto do confronto entre poderes e tal distinção é, portanto, de pouca ajuda.

\section{Um modelo de instituições endógenas}

O fato de o paradoxo descrito na seção anterior ter sido ignorado pela literatura institucional por tanto tempo sugere que os cientistas políticos que trabalham com essas questões confiaram implicitamente em pressupostos que nunca se preocuparam em explicitar. A maioria deles concordaria com a idéia de que o impasse político representa uma ameaça à estabilidade democrática (somente sob certas circunstâncias). O problema é que a literatura existente deixou de especificar a natureza dessas pré-condições.

Para enfrentar esse problema, é importante perceber que os dois corolários da tese do impasse baseiam-se em pressupostos diferentes quanto à estrutura de preferência dos atores políticos que se defrontam com um trade of entre status-quo das políticas e status-quo do regime, entre buscar resultados substantivos e a preservação das regras que constrangem a tomada de decisões. O argumento dos 
perigos do presidencialismo pressupôs que entre os atores com veto, as preferências por políticas orientam as preferências quanto às instituições (isto é, tipo de regime). Na ausência de mudança política, espera-se que a frustração induza os atores-chaves a se desfazerem das regras e dos procedimentos existentes, que percebem como meros constrangimentos criados pela constituição, a fim de alcançar suas metas substantivas. Em contraste, o argumento da estabilidade das políticas toma por suposto que as instituições são exógenas e fixas. Não se pressupõe que alguma questão política seja suficientemente significativa para transformar as regras constitucionais numa variável endógena, porque as preferências por políticas não orientam as preferências por tipos de regimes.

A natureza contraditória desses dois pressupostos está na origem do paradoxo do impasse documentado na seção anterior. A questão não é se um pressuposto é correto e o outro falso, mas como transformar esses pressupostos em tema de investigação empírica. Devemos compreender porque algumas disputas sobre políticas contaminam acordos preexistentes quanto a escolhas institucionais enquanto, em outros casos, as escolhas sobre instituições permanecem protegidas das disputas por políticas.

\section{O modelo}

Considere-se uma sociedade com um número $\mathrm{N}$ de partidos - grupos de cidadãos organizados para perseguir políticas diferentes - que competem pelo controle de dois poderes do governo, o executivo e o legislativo. A composição dos poderes é determinada por um mecanismo institucional (por exemplo, eleições livres, eleições manipuladas, uma loteria) que seleciona o chefe do executivo e os membros do congresso coletivo dentre aqueles grupos partidários a intervalos regulares (ou rodadas). Se o executivo e (a maioria do) congresso concordam quanto à perspectiva partidária, obtém-se a coordenação política e a proposta do partido dominante é implementada. Se assim não for, ocorre o impasse e prevalece uma política reversível. Devemos pressupor por enquanto que cada partido prefere suas próprias políticas ao ponto reversível e o ponto reversível às políticas de seus adversários.

Se não estão satisfeitos com o resultado das políticas, os partidos podem adotar uma de duas estratégias: a) aguardar até a próxima rodada, esperando que a nova composição dos dois poderes lhes será favorável, ou b) revoltar-se contra o sistema, transformando a disputa por políticas num conflito mais amplo para redefinir o mecanismo de seleção existente. Repetindo Dahl, chamarei a primeira estratégia de "tolerância" (das instituições existentes), ou simplesmente "espera", e 
a segunda estratégia de uma "revolta", um "golpe", ou uma tentativa de suprimir a ordem institucional existente (DAHL, 1971). Supõe-se que o sucesso de uma revolta pode ser obtido com uma probabilidade conhecida e que ele garante a implementação das políticas mais desejadas, enquanto a derrota de uma revolta levará à imposição das políticas de algum outro partido (portanto, menos desejável).

Assim, qualquer ator partidário pode ser descrito por um vetor de valores de probabilidade $\mathbf{Z}_{i, m}=\left[p_{i, m}, q_{i, m}, c_{i}\right]$, em que $i$ identifica o i-ésimo partido, $m$ refere-se ao mecanismo de seleção atualmente empregado, $p$ representa a probabilidade de que o partido controlará o executivo em alguma rodada, $q$, a probabilidade de que o mesmo partido controlará o congresso, e c, a probabilidade de sucesso do partido numa revolta. Observe-se que, embora a soma de $p$ e a soma de $q$ através dos partidos seja igual a um, o valor de c é independente para cada i (e, presumivelmente, não varia com o mecanismo de seleção, embora pudesse).

Esse modelo introduz os principais elementos discutidos na seção anterior de forma estilizada: os partidos integram dois ramos do governo, de tal modo que criam unidade de propósito e mudança de políticas $\left(\sim S_{p}\right)$ ou separação de propósito e impasse $\left(S_{P}\right)$. Por sua vez, eles podem reagir contra qualquer desses resultados respeitando as instituições existentes (criando assim estabilidade de regime $\left(S_{R}\right)$ ou deflagrando um golpe $\left(\sim S_{R}\right)$. Dado esse cenário, sob qualquer processo de seleção $m$, o partido $i$ pode esperar implementar suas políticas preferidas com probabilidade $\mathrm{p}_{i} \mathrm{q}_{i}$, e a probabilidade de impasse político durante qualquer rodada é $P\left(S_{p}\right)=1-\Sigma p_{i} q_{i}$. A instabilidade de regime ocorrerá sempre que a utilidade esperada da espera for menor do que a utilidade esperada da revolta por pelo menos um ator partidário.

O modelo propicia alguns insights importantes sobre as causas da estabilidade do regime. Sustento que a tolerância tem menor probabilidade de se tornar uma estratégia dominante quando: a) os atores são unilateralmente impacientes; b) as instituições existentes inclinam-se sistematicamente em favor de um setor; c) o número de atores partidários aumenta ou d) a probabilidade de sucesso em caso de revolta é alta.

\section{Impaciência}

A impaciência acontece quando o fator de desconto para políticas implementadas em rodadas futuras é grande, tornando o custo da inação no presente alto demais. Observe-se, no entanto, que a impaciência pode ter dois efeitos opostos. A impaciência "neutra" levará os partidos à conclusão de que qualquer política hoje é melhor do que suas políticas preferidas amanhã. Essa 
situação inverte a estrutura de preferências descrita acima, tornando uma boa política melhor do que uma ruim e esta última melhor do que o ponto reversível. Nesse contexto, o problema de coordenação é resolvido por quem estabelece a agenda; a instituição iniciadora simplesmente impõe suas políticas preferidas (TSEBELIS e MONEY, 1997). Por outro lado, a impaciência "unilateral" levará os atores a concluir que a inação é tão ruim quanto uma política indesejável. Nesse caso, a estrutura de preferências é simplesmente dicotômica porque o impasse significa derrota política. O partido unilateralmente impaciente tentará provocar uma mudança de idéia (uma reorganização da composição) na instituição inflexível, ou então tentará alterar o processo de seleção subjacente assim que possível.

\section{Instituições abertas versus fechadas (perdedores "aleatórios" versus sistemáticos)}

Minha hipótese é que um mecanismo de seleção "fechado" (um processo claramente inclinado a favor de um setor) criará um cenário institucional que é menos propenso ao impasse, mas, paradoxalmente, com maior probabilidade de colapso. As instituições abertas complicarão a realização de ganhos importantes para qualquer partido, mas certamente protegerão todos os partidos de grandes perdas no longo prazo. Como ilustração, consideremos o modelo anterior com apenas dois partidos. Dentro de um processo de seleção perfeitamente aberto (baseado no lançamento de uma moeda para o alto, por exemplo), a coordenação sobre novas políticas acontecerá no longo prazo $50 \%$ das vezes e cada um dos dois grupos verá sua opção preferida realizada com uma probabilidade de 0.25 . Em contraste, se eleições manipuladas permitem que proponentes de uma política ganhem as eleições presidenciais e legislativas com uma probabilidade fixa de .90, o impasse será evitado em $82 \%$ das vezes, mas a preferência do partido dominante prevalecerá em $99 \%$ dessas ocasiões. Os proponentes da política conflitante poderão bloquear a implementação em $19 \%$ dos casos e terão a sorte de realizar sua opção preferida em apenas $1 \%$ das ocasiões. Para esse partido, o impasse das políticas não é o principal problema. Os perdedores sistemáticos consideram inaceitável a estrutura institucional subjacente e por isso contestarão as instituições como forma de enfrentar os principais conflitos quanto às políticas. 


\section{Multipartidarismo}

A idéia de que instituições abertas (por exemplo, eleições justas) evitam que as disputas sobre políticas se tornem disputas sobre a natureza do regime introduz uma nova flexão na afirmação de que os sistemas multipartidários são mais propensos ao impasse e, portanto, à ruptura do regime (MAINWARING, 1993). De um lado, o impasse executivo-legislativo é mais provável quando o sistema partidário é fragmentado e o presidente é incapaz de controlar uma maioria legislativa (CHEIBUB, 2002). Em termos do modelo discutido acima, o multipartidarismo reduziria os valores de $p$ e de $q$, diminuindo assim a utilidade esperada da tolerância e criando incentivos para a revolta. Por outro lado, sistemas de partido hegemônico costumam indicar uma manipulação do processo eleitoral, o que facilita a transformação de qualquer disputa política numa crise de legitimidade institucional. Assim, a não ser que controlemos a natureza do regime, - multipartidarismo pode ter efeitos inconsistentes sobre a estabilidade presidencial porque serve como um agente para duas variáveis com efeitos opostos: a propensão ao impasse e a abertura do processo de seleção.

\section{Probabilidade de supressão}

O motivo porque uma maior probabilidade de sucesso militar estimula uma revolta explica-se por si mesmo e não merece muita discussão. Vale a pena observar que se as revoltas não tivessem custos, é provável que as instituições não sobrevivessem em qualquer circunstância. Porém, as revoltas exigem organização e seu fracasso pode levar à morte dos rebeldes, perda de liberdade ou - o que é mais relevante para este modelo - à vitória do setor oposto e a imposição de sua política preferida.

\section{Uma ilustração}

Nesta seção, refino os pressupostos para abrir espaço para uma demonstração simples. Consideremos os partidos A e B que promovem as políticas a e $b$ respectivamente. Os ganhos iniciais são estabelecidos em 100, 50 e 0, para a política preferida, o ponto reversível e a política do oponente. Em casos de impaciência (unilateral), o ganho para o ponto reversível cai para 0 . O processo de seleção existente determina que o executivo e o legislativo serão controlados por membros de A com probabilidades $\mathrm{p}$ e q, e por membros de B com probabilidades 1-p e 1-q. A probabilidade da política a ser implementada em qualquer momento 
dado do tempo é, assim, pq, com (1-p)(1-q) representando a probabilidade de $b$ ser adotada e 1-[pq+(1-p)(1-q)] sendo a probabilidade de impasse. Dentro dos ganhos apresentados acima, por exemplo, a utilidade esperada de tolerância para o partido A é, na ausência de impaciência, $p q^{*} 100+[1-p q+(1-p)(1-q)]^{* 50}$. Se $c(a)$ denota a probabilidade de um golpe bem sucedido em apoio da política a, a utilidade esperada da revolta para o partido A é igual a $c(a)^{*} 100+(1-c(a))^{*} 0$.

A figura 1 exibe a relação entre ganhos esperados e a natureza do processo de seleção. Para os propósitos dessa ilustração, pressupomos, exceto indicação contrária, que $\mathrm{p}=\mathrm{q}$ e que a probabilidade de um golpe vitorioso em apoio de qualquer política, $c(a)=c(b)$, é fixada em 0.3. Valores de p próximos de .50 indicam incerteza sobre o processo de seleção e, portanto, abertura institucional. Os valores de $p$ que se aproximam de um indicam instituições inclinadas a favor de $A$; valores que se aproximam de zero, uma inclinação a favor de B.

Figura 1

Utilidade esperada para partidos que toleram ou tentam suprimir instituições existentes, sendo dados p, q, e expectativas de impasse

\subsection{Efeitos da impaciência e do multipartidarismo}

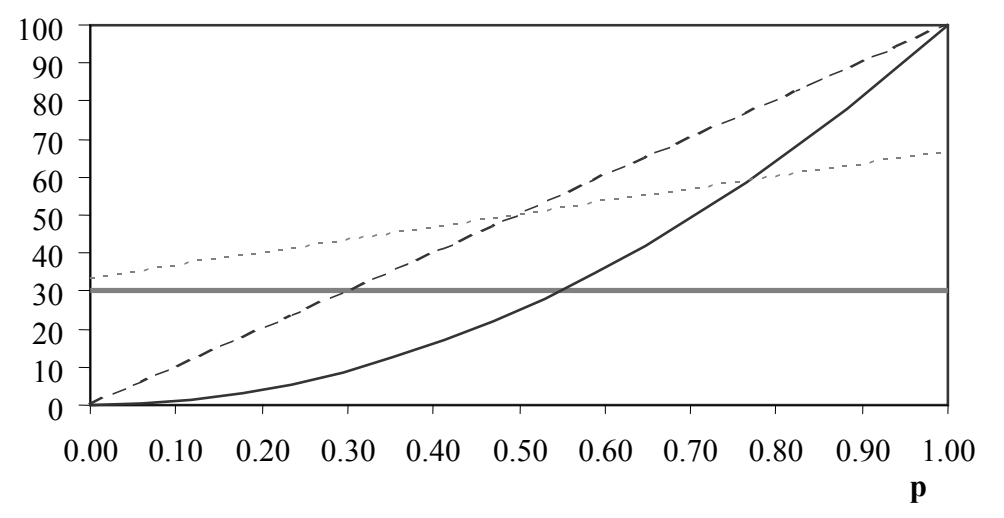

- Golpe ${ }^{----A}$ A (Paciência) ——A (Impaciência) ${ }^{\cdots \cdots}$ A com q=1/3 


\subsection{Efeitos de instituições fechadas e impasse}

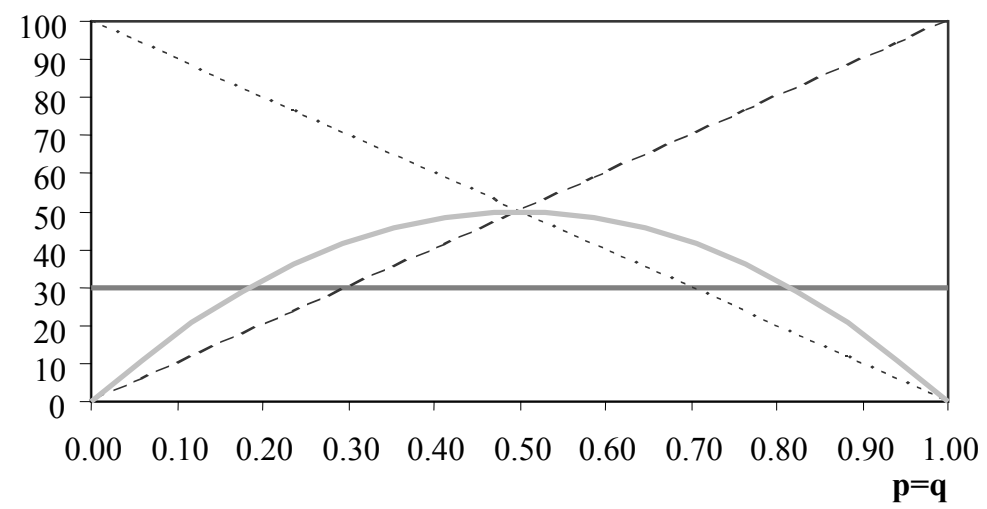

$\longrightarrow$ Golpe $^{----}$A (Paciência) ${ }^{\cdots \cdots} \cdot$ B (Paciência) $\square$ (\% Impasse)

Nota: Os ganhos são arbitrariamente estabelecidos como 100 unidades para a política preferida, 50 para o ponto reversível (0 no caso de impaciência), e 0 para política rejeitada. Valores para $c(a)=c(b)=.30$

Os dois gráficos ilustram a hipótese discutida acima. A Figura 1.1 mostra que um partido unilateralmente impaciente (com seu ganho esperado representado pela curva ascendente) tem menor probabilidade de respeitar a ordem institucional do que um partido paciente (representado pela diagonal pontilhada) ${ }^{9}$. Essa figura sugere também o que aconteceria se um terceiro partido entrasse na disputa congressional e se $q=1 / 3$ para todos os três partidos. O multipartidarismo reduz significativamente o benefício esperado da tolerância institucional para $A$, exceto se o mecanismo de seleção for inclinado a favor do partido (caso em que uma maior probabilidade de impasse serve como proteção contra a política $b$, mas a legitimidade total das instituições existentes ainda fica em questão).

\footnotetext{
9 É tentador interpretar a impaciência unilateral em termos de aversão a risco. Porém, isso pode ser enganador, porque os jogadores nesse modelo sempre assumem riscos - eles devem escolher entre uma loteria institucional e uma militar. A aversão a riscos só faz sentido se pressupusermos uma renda garantida. Assim, se consideramos intuitivamente o golpe como uma "aposta", mas supomos que as instituições propiciam um nível fixo de ganho político, um jogador impaciente parece ser propenso ao risco. Mas se supomos certeza quanto aos ganhos relacionados com um golpe militar, o jogador impaciente parece ser avesso ao risco.
} 
O segundo gráfico representa a relação subjacente entre abertura institucional, incentivos para tolerância e impasse político. As diagonais refletem os ganhos esperados para os partidos $A$ e $B$ quando $p=q$. Na medida em que o mecanismo de seleção se inclina a favor de um setor, seus oponentes ficam cada vez mais estimulados a contestar a ordem institucional. Os incentivos mútuos para tolerar as instituições existentes encontram-se no ponto em que a probabilidade de impasse político (representado pela curva cinza ao fundo) é maior. Essa situação corresponde a um puro equilíbrio rustowiano, em que ambos os setores trocam qualquer ambição de sucesso total pela proteção institucional contra a derrota total (RUSTOW, 1970). Ambas as figuras ilustram o papel independente desempenhado pelas expectativas de sucesso militar. Sob expectativas de sucesso maiores do que 0.5, nenhum arranjo institucional sobreviverá porque pelo menos um setor terá sempre incentivos para se revoltar.

\section{Análise empírica}

Com o objetivo de testar as hipóteses apresentadas acima, analiso o desempenho de dezenove países presidencialistas do hemisfério ocidental entre 1950 e $2000^{10}$. As unidades de análise são anos-regime presidencial, definidos como aqueles anos em que um presidente (um indivíduo no papel de chefe de Estado e governo) e um congresso eleito coexistem.

A medida de instabilidade de regime $\left(\sim S_{R}\right)$ é uma variável dummy que indica a ocorrência de um golpe militar em qualquer ano dado. Defino golpe como qualquer episódio em que a intervenção militar derruba o presidente ou fecha o congresso, ou ambos. Essa definição inclui 1) golpes militares tradicionais que fecham ambos os ramos do governo; 2) ações militares lideradas pelo presidente contra o congresso; e 3) "intervenções moderadoras" de oficiais militares que desejam derrubar o presidente, mas não fecham o legislativo. Um total de 42 golpes foram codificados para um total de 843 anos-regime.

\footnotetext{
10 Os países do estudo são Argentina (num total de 37 anos), Bolívia (36), Brasil (50), Chile (35), Colômbia (46), Costa Rica (51), República Dominicana (49), Equador (41), El Salvador (48), Guatemala (48), Honduras (41), México (51), Nicarágua (45), Panamá (48), Paraguai (51), Peru (42), Estados Unidos (51), Uruguai (25) e Venezuela (48). Cuba (1950-59) foi excluída devido à falta de dados macroeconômicos.
} 


\section{Impaciência}

Utilizo dois agentes para impaciência. O primeiro, correspondendo à impaciência "neutra", é uma variável dicotômica para situações econômicas críticas em que a inflação superou a marca dos $100 \%$. A ameaça de hiperinflação supostamente leva a maioria dos setores ao "domínio das perdas" e os estimula a aceitar qualquer política a fim de enfrentar o problema (WEYLAND, 2002). O segundo agente indica casos de impaciência "unilateral" identificando crises presidenciais, ou casos em que um dos dois poderes torna explícito seu desejo de reorganizar o outro (PÉREZ-LIÑÁN, 2003). As crises presidenciais estão codificadas como uma variável dicotômica com um valor de um para cada ano em que os líderes do congresso ameaçaram tirar o presidente do cargo ou o executivo ameaçou com a dissolução do congresso. Tais episódios não envolvem necessariamente uma ameaça de intervenção militar - o congresso pode pedir impeachment, ou o presidente pode pedir uma reforma constitucional - mas indicam claramente a má vontade de um poder coexistir com o outro. Das 41 crises da amostra, somente 12 (29\%) levaram a um golpe militar. Para evitar problemas de contaminação com a variável dependente, codifiquei nessa categoria apenas casos em que o histórico mostrava claramente que um confronto entre os poderes precedera o golpe (se houve algum). Casos em que o conflito entre poderes parecia ser endógeno ao próprio golpe (Argentina em 1962 e 1976, Brasil em 1955, Equador em 2000, Guatemala em 1957, Panamá em 1988, Paraguai em 1954) foram codificados como zero para favorecer a hipótese nula ${ }^{11}$.

\section{Instituições fechadas}

Conquanto a literatura existente tenha se concentrado nas democracias presidencialistas sobreviventes por razões normativas, o impasse executivo. legislativo é possível em qualquer regime em que os dois poderes tenham autonomia suficiente para se confrontarem. Se as democracias presidencialistas comportam-se de modo diferente das semidemocracias (ou não-democracias) presidencialistas, isso é uma questão de pesquisa empírica. Utilizo dois indicadores de instituições fechadas. O primeiro é uma variável dicotômica que mostra a

\footnotetext{
${ }^{11}$ A situação típica é aquela em que os oficiais militares derrubam o presidente e o congresso legaliza o golpe, aceitando a "resignação" do chefe do executivo e designando um substituto. A partir dos registros históricos, é difícil decidir se os líderes do congresso nesses casos faziam parte de uma conspiração civil-militar - indicando que um conflito executivo-legislativo precedeu o golpe - ou se apenas aderiram ao golpe porque tinha poucas escolhas - indicando que o conflito entre poderes era um subproduto da instabilidade do regime.
} 
existência de um partido hegemônico no legislativo. A dummy adota o valor de um quando o número efetivo de partidos na câmara baixa (ou única) é menor do que 1.5. Essa situação corresponde a casos em que o partido governante controla mais de $79 \%$ dos assentos, uma concentração de poder que torna suspeito o processo eleitoral e obsta qualquer tentativa da minoria de evitar a mudança de políticas. Em teoria, o partido hegemônico no congresso poderia ser diferente do partido do presidente, mas nenhum caso na amostra corresponde a uma situação de governo dividido. O segundo indicador mede a probabilidade de que atores partidários com veto alcançarão suas posições por meio de um processo eleitoral abertamente manipulado. Esse indicador adota um valor de 0 para todos os países codificados como democráticos, e o valor de 1 para todos os países codificados como autoritários na escala de Mainwaring et al. (MAINWARING, BRINKS e PÉREZ-LIÑÁN, 2001). Países semidemocráticos com graus diferentes de incerteza recebem um valor equivalente aos escore Polity $\mathrm{V}$ invertido recodificado para variar entre 0 e $1^{12}$.

\section{Multipartidarismo}

O multipartidarismo é definido como qualquer sistema partidário com um número efetivo de partidos maior do que 3.0 na câmara baixa (ou única). Prefere-se o uso de indicador dicotômico ao de número efetivo bruto de partidos por três motivos. Primeiro, ele não supõe que uma mudança de unidade de um para dois partidos terá o mesmo efeito do que de dois para três partidos, ou de seis para sete partidos. Segundo, nos permite distinguir os efeitos desestabilizadores criados por partidos em demasia (multipartidarismo) daqueles criados por escassez de partidos (o caso de hegemonia discutido acima). Terceiro, nos possibilita evitar o problema das maiorias efetivas, necessárias para aprovar legislação. Por exemplo, se três partidos coesos controlam um terço dos assentos legislativos cada um, qualquer lei precisa ser aprovada por uma maioria de dois terços. Se, ao contrário, vinte partidos coesos controlam um vigésimo dos assentos cada um, a legislação pode ser aprovada com apenas 55\% dos votos. Assim, um número maior de partidos pode aumentar a probabilidade de impasse ao aumentar os custos da montagem de coalizões, mas pode reduzir as chances de impasse ao diminuir o número real necessário para obter uma maioria ${ }^{13}$.

\footnotetext{
12 Quaisquer operacionalizações alternativas dessa variável (usando os escores Polity IV brutos, ou tratando a escala de Mainwaring como uma variável contínua) produziram resultados equivalentes. Essa variável foi sempre codificada levando em conta o valor para o ano anterior, pois os valores para o ano corrente já refletem os efeitos de um golpe militar.

13 A questão complexa da formação de coalizões (para não falar de disciplina partidária) está fora da estrutura simples do modelo aqui apresentado. Tendo em vista nosso cenário, se os partidos $\mathrm{i}$ e $\mathrm{j}$
} 


\section{Probabilidade de supressão}

A probabilidade de sucesso de qualquer revolta é sempre determinada pelas condições locais e é difícil de prever, mesmo para os conspiradores envolvidos. Porém, é verdade que fatores históricos e internacionais tendem a constranger as chances gerais de uma intervenção militar. Por exemplo, entre 1950 e 1977, 7\% dos casos da amostra sofreram um golpe militar, mas com a "terceira onda" de democratização iniciada em 1978, esse número caiu para 3\%. Uso dois agentes para avaliar a propensão histórica total à supressão institucional. 0 primeiro concentra-se no curto prazo e mede a proporção de países da amostra que sofreram um golpe militar no ano anterior. $\mathrm{O}$ segundo mede tendências de longo prazo olhando para o ambiente democrático, aponta a proporção de países da amostra (exceto para o país sendo codificado) que foram democráticos em qualquer ano dado. Ambas as medidas supõem que os atores levam em conta os "sinais dos tempos" quando avaliam as chances de sucesso de uma revolta.

Os modelos incluem também uma medida de PIB per capita (em dólares americanos de 1995) para o ano anterior e de crescimento econômico durante o ano anterior como variáveis de controle ${ }^{14}$. Para controlar efeitos de unidade, fiz rodar um modelo adicional de efeitos fixos. A Tabela 1 apresenta os resultados da análise de regressão logística. Os dois primeiros modelos incluem somente democracias e semidemocracias da classificação de Mainwaring et al (correspondendo, grosso modo, ao conjunto de democracias na classificação de Przeworski et al). Os modelos restantes incluem outros trezentos casos de presidencialismo abertamente não-democrático. Tal como esperado, a presença de uma crise presidencial está relacionada de modo consistente com a probabilidade de instabilidade do regime, mas níveis de inflação extremamente altos têm efeitos insignificantes (especificações alternativas com limiares estabelecidos a 50\%, $300 \%$ e $1000 \%$ produziram resultados equivalentes). Por sua vez, instituições fechadas (isto é, menos democráticas) estão relacionadas com uma maior probabilidade de rebelião militar. A significância da dummy do partido hegemônico

concordam com um programa comum, eles se tornam um ator novo, $c$, aumentando sua alavancagem legislativa para $q_{c}=q_{i}+q_{j}$ (e presumivelmente suas chances de controle da presidência para $p_{c}=p_{i}+p_{j}$ ). $A$ inclusão no modelo das perdas política e dos custos de transação relacionados com essa fusão exigiria uma maior complexidade. Porém, as coalizões são um fator importante nos regimes presidencialistas (ver ALTMAN, 2000; AMORIM NETO, 2002) e alguns dos insights deste modelo sugerem que elas podem ser uma força efetiva na redução da probabilidade de instabilidade do regime.

14 Séries do World Development Indicators, 2001. Valores do PIB para 1950-1959 foram estimados com base em dados da CEPAL para a América Latina e nas Penn World Tables para os Estados Unidos. 
diminui depois que uma medida de democratização é introduzida, presumivelmente porque alguns regimes autoritários permitem a existência pró-forma de vários partidos de oposição e porque os sistemas de partido predominante (aqueles em que um partido controla o legislativo, mas o processo eleitoral ainda é considerado aberto) estimularão mais tolerância de parte da oposição descontente. Depois que controlamos o grau de abertura do processo de seleção, o efeito do multipartidarismo é positivo e significante, mostrando que os atores partidários têm menores incentivos para tolerar as instituições existentes quando as chances de impasse são maiores. De acordo com os resultados, as expectativas de sucesso futuro com instituições abertas podem compensar os efeitos da impaciência e do multipartidarismo. Assim, devemos esperar que o impasse político crie uma séria ameaça para qualquer regime com credenciais democráticas fracas, mas em menor escala para aqueles baseados em eleições transparentes. 


\section{Tabela 1}

Modelos de regressão logística de instabilidade de regime

\begin{tabular}{|c|c|c|c|c|c|c|}
\hline \multirow[b]{2}{*}{ Preditor } & \multicolumn{3}{|c|}{$\begin{array}{c}\text { Democracias e } \\
\text { Semi-Democracias }\end{array}$} & \multicolumn{2}{|c|}{ Todos os casos } & \multirow{2}{*}{$\begin{array}{c}\text { Efeitos fixos } \\
\text { (todos os } \\
\text { casos) } \\
5\end{array}$} \\
\hline & 1 & & 2 & 3 & 4 & \\
\hline \multicolumn{7}{|l|}{ Impaciência } \\
\hline Inflação> $100 \%$ & $\begin{array}{r}0.500 \\
(1.048)\end{array}$ & & $\begin{array}{r}0.882 \\
(1.088)\end{array}$ & $\begin{array}{l}-0.348 \\
(0.865)\end{array}$ & $\begin{array}{r}-0.175 \\
(0.841)\end{array}$ & $\begin{array}{l}-0.451 \\
(0.922)\end{array}$ \\
\hline $\begin{array}{l}\text { Crise } \\
\text { presidencial }\end{array}$ & $\begin{array}{r}3.127 \\
(0.589)\end{array}$ & $* * *$ & $\begin{array}{l}3.6988^{* * *} \\
(0.690)\end{array}$ & $\begin{array}{l}2.507^{* * *} \\
(0.431)\end{array}$ & $\begin{array}{l}2.777^{* * *} \\
(0.463)\end{array}$ & $\begin{array}{l}2.898^{* * *} \\
(0.524)\end{array}$ \\
\hline \multicolumn{7}{|l|}{ Instituiccões fechadas } \\
\hline Partido hegemônico & $\begin{array}{r}2.377 \\
(1.085)\end{array}$ & & $\begin{array}{r}0.283 \\
(1.104)\end{array}$ & $\begin{array}{l}1.427^{* * *} \\
(0.482)\end{array}$ & $\begin{array}{l}0.916 * \\
(0.492)\end{array}$ & $\begin{array}{r}0.985 * \\
(0.573)\end{array}$ \\
\hline Regime & & & $\begin{array}{l}4.835^{* * *} \\
(1.356)\end{array}$ & & $\begin{array}{l}1.450^{* * *} \\
(0.490)\end{array}$ & $\begin{array}{r}1.058 \text { * } \\
(0.606)\end{array}$ \\
\hline \multicolumn{7}{|l|}{ Propensão à revolta } \\
\hline Ambiente & $\begin{array}{r}-5.221 \\
(2.013)\end{array}$ & $* * *$ & $\begin{array}{l}-5.810 * * \\
(2.515)\end{array}$ & $\begin{array}{l}-2.924 * * \\
(1.433)\end{array}$ & $\begin{array}{r}-1.984 \\
(1.608)\end{array}$ & $\begin{array}{l}-3.305 * \\
(1.915)\end{array}$ \\
\hline Golpes (t-1) & & & $\begin{array}{r}4.257 \\
(4.494)\end{array}$ & & $\begin{array}{r}2.460 \\
(2.807)\end{array}$ & $\begin{array}{r}2.432 \\
(2.967)\end{array}$ \\
\hline Multipartidarismo & $\begin{array}{r}1.478 \\
(0.653)\end{array}$ & & $\begin{array}{l}1.745^{* * *} \\
(0.677)^{*}\end{array}$ & $\begin{array}{l}1.233^{* * *} \\
(0.431)\end{array}$ & $\begin{array}{l}1.4766^{* * *} \\
(0.452)\end{array}$ & $\begin{array}{l}1.302 \\
(0.587)\end{array}$ \\
\hline PIB Per Capita (t-1) & $\begin{array}{l}-0.056 \\
(0.097)\end{array}$ & & $\begin{array}{l}-0.026 \\
(0.097)\end{array}$ & $\begin{array}{l}-0.107 \\
(0.101)\end{array}$ & $\begin{array}{r}-0.046 \\
(0.094)\end{array}$ & $\begin{array}{r}0.219 \\
(0.385)\end{array}$ \\
\hline Crescimento (t-1) & $\begin{array}{r}0.045 \\
(0.071)\end{array}$ & & $\begin{array}{r}0.048 \\
(0.066)\end{array}$ & $\begin{array}{l}-0.037 \\
(0.044)\end{array}$ & $\begin{array}{r}-0.034 \\
(0.043)\end{array}$ & $\begin{array}{r}-0.012 \\
(0.046)\end{array}$ \\
\hline Dummies dos países & & & & & & $\ldots$ \\
\hline Constante & $\begin{array}{l}-2.837 \\
(0.971)\end{array}$ & $* * *$ & $\begin{array}{l}-4.051^{* * *} \\
(1.204)^{2}\end{array}$ & $\begin{array}{l}-2.713^{* * *} \\
(0.670)\end{array}$ & $\begin{array}{l}-4.1711^{* * *} \\
(0.874)\end{array}$ & $\begin{array}{r}-3.424 \\
(2.371) \\
\end{array}$ \\
\hline Nagelkerke $\mathrm{R}^{2}$ & .324 & & .413 & .192 & .226 & .318 \\
\hline $\mathrm{N}$ & 543 & & 543 & 843 & 843 & 843 \\
\hline
\end{tabular}


A Tabela 1 sugere também que as variáveis econômicas não estão relacionadas com a estabilidade presidencial, confirmando a asserção de Przeworski de que a ruptura do presidencialismo ocorre "em países ricos tanto quanto em pobres, quando a economia declina e quando se expande" (PRZEWORSKI et al, 2000, p. 132). O ambiente internacional parece ser um fator significativo no constrangimento de golpes militares (mas não a experiência de outros países no passado imediato), enquanto os efeitos de unidade são desprezíveis.

\section{Discussão}

Os resultados apresentados na Tabela 1 iluminam algumas das anomalias que desafiaram as interpretações do impasse executivo-legislativo no passado. Primeiro, há a questão da excepcionalidade dos Estados Unidos (única democracia presidencialista sem propensão para a instabilidade política). Riggs (1988) sustentou que dispositivos "para-constitucionais" permitiram a sobrevivência da democracia americana apesar de seu desenho presidencialista e Linz, de modo semelhante, apontou que "extrapolaria os limites deste ensaio explicar a singularidade das instituições e práticas políticas americanas que limitaram o impacto de tais conflitos [entre poderes]" (LINZ, 1994, p. 7). As interpretações desse tipo costumam tomar a forma de explicações ad hoc, com pouca relevância para a questão teórica geral em debate. Em contraste, o argumento desenvolvido nas páginas anteriores ajuda a explicar o desempenho do presidencialismo americano sem tirar o coelho da excepcionalidade do chapéu analítico.

Desde 1950, somente em duas oportunidades (1974 e 1998) a ameaça de crise entre os poderes esteve à vista nos EUA e mesmo quando as questões partidárias estimularam um poder a desafiar a sobrevivência do outro (como no final de 1998, com o impeachment de Clinton), a presença de instituições abertas evitou que as disputas políticas de curto prazo contaminassem as preferências de longo prazo em relação ao regime. Os resultados empíricos refletem essa situação: a probabilidade predita média de um golpe nos Estados Unidos nos 51 anos em estudo é de 0.0057, prevendo uma revolta contra o sistema a cada 176 anos $^{15}$.

\footnotetext{
15 Um enigma similar foi a excepcionalidade chilena antes de 1973 , mas pelo motivo oposto. Mainwaring (1993) observou que "somente o Chile tinha um verdadeiro sistema multipartidário entre as democracias presidencialistas estáveis" e concluiu que "com essa combinação institucional, a estabilidade democrática depende em larga medida do desejo das elites e dos cidadãos de fazer acordos e criar instituições democráticas duradouras". A probabilidade predita de golpe para o período 1950-72 é de 0.048 para o Chile, em comparação com 0.066 para a Argentina e 0.106 para o Brasil.
} 
Um segundo enigma significativo foi criado pela capacidade dos regimes presidencialistas suportarem o confronto entre poderes durante a última década. No começo da década de 1990, Scott Mainwaring escreveu que "só excepcionalmente um executivo é tirado do cargo antes do fim de seu mandato sem uma ruptura de regime nos sistemas presidencialistas" (MAINWARING, 1993, p.208), mas no final da década ele reconheceria que "os casos latino-americanos criaram um novo modelo para como enfrentar crises institucionais em sistemas presidencialistas. O impeachment é um caminho custoso, mas é melhor do que um golpe..." (MAINWARING, 1999, p. 110).

A recente proliferação de impeachments na América Latina sugere que, embora continuem acontecendo crises constitucionais, as elites políticas nos sistemas presidencialistas estão encontrando cada vez mais maneiras de resolver essas crises sem contestar as regras básicas do jogo. Uma explicação completa desse fenômeno talvez esteja além do alcance do modelo apresentado aqui, mas essa tendência é coerente com a crescente abertura das instituições latino. americanas após a terceira onda de democratização. As crises entre executivos e legislativos preservam hoje seu potencial de desestabilizar o presidencialismo (por exemplo, Peru em 1992 ou Guatemala em 1993), mas, tal como nos EUA, esse potencial é cada vez mais compensado pela crença de que alguns atores partidários adquiriram um direito legal de desafiar o executivo ou vetar suas políticas e que seus oponentes terão uma chance justa de assumir o poder executivo no futuro. A figura 1 (baseada no modelo 4) ilustra como a probabilidade prevista de um golpe entre regimes presidencialistas do hemisfério ocidental declinou de uma média anual de 6,4\% durante 1950-1977 para 3,1\% nos anos posteriores à terceira onda de democratização. 
Figura 2

Probabilidade predita média de golpe, $\mathrm{P}\left(\sim \mathrm{S}_{\mathrm{R}}\right)$, por ano

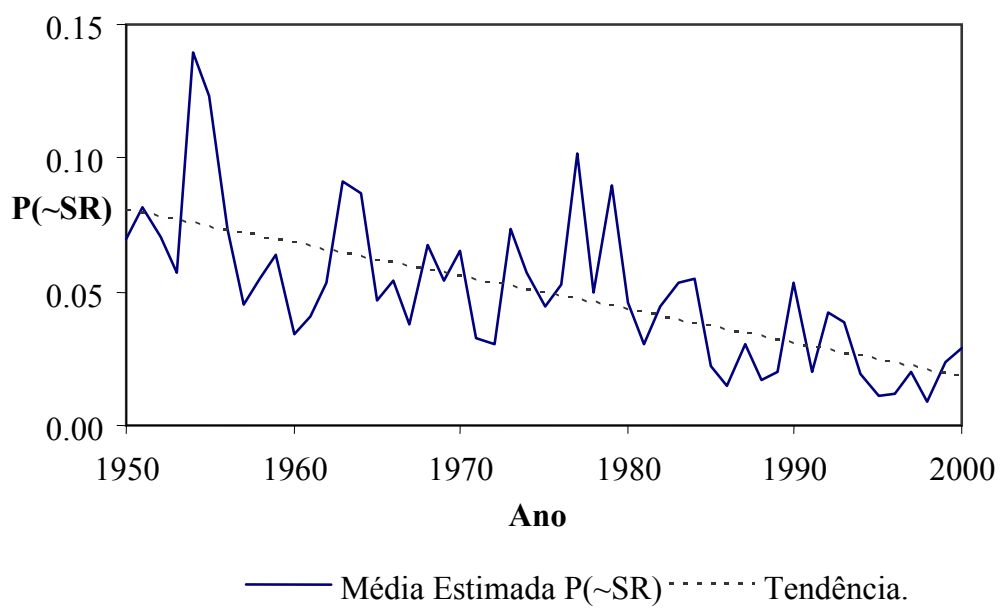

Os resultados deste trabalho abrem três linhas principais de pesquisa. Primeiro, talvez precisemos revisar de forma crítica a conexão teórica entre estabilidade de políticas e instabilidade de regime. Segundo, é necessário identificar mais situações em que seja provável que as preferências quanto às políticas possam sobrepor-se ao status quo institucional. Terceiro, parece que os estudos sobre presidencialismo precisam enfocar casos de democracia assim como casos de semi ou não-democracia presidencialista. Na medida em que as constituições presidencialistas criam alguns "perigos", eles podem constituir uma ameaça maior para os regimes com legitimidade eleitoral fraca do que para as democracias plenas, em que os vetos são percebidos como um resultado legítimo da competição pelo poder. Freios e contrapesos podem revelar-se um perigo maior para a sobrevivência de homens fortes do que para a de líderes democráticos. 


\section{Bibliografia}

ALTMAN, David. The Politics of Coalition Formation and Survival in Multi-Party Presidential Democracies - The Case of Uruguay, 1989-1999. Party Politics, 6 (3), p. 259-283, 2000.

AMES, Barry. The Deadlock of Democracy in Brazil. Ann Arbor: The University of Michigan Press, 2001.

AMORIM NETO, Octavio. Presidential Cabinets, Electoral Cycles, and Coalition Discipline in Brazil. In: MORGENSTERN, S. e NACIF, B. (eds.). Legislative Politics in Latin America. Cambridge:

Cambridge University Press, p. 48-78, 2002.

BINDER, Sarah A. The Dynamics of Legislative Gridlock, 1947-96. The American Political Science Review , 93 (3), p. 519-533, 1999.

CHEIBUB, José Antonio. Minority Governments, Deadlock Situations, and the Survival of Presidential Democracies. Comparative Political Studies, 35 (3), p. 284-312, 2002.

CHEIBUB, José Antonio e LIMONGI, Fernando. Democratic Institutions and Regime Survival: Parliamentary and Presidential Democracies Reconsidered. Annual Review of Political Science, 5, p.151-179, 2002.

COX, Gary W. e MCCUBBINS, Mathew D. The Institutional Determinants of Economic Policy Outcomes. In: HAGGARD, S. e MCCUBBINS, M. D. (eds.). Presidents, Parliaments, and Policy. Cambridge: Cambridge University Press, p. 21-63, 2001.

DAHL, Robert A. Polyarchy: participation and Opposition. New Haven: Yale University Press, 1971.

DION, Douglas. Evidence and Inference in the Comparative Case Study. Comparative Politics, 30 (2), p. 127-146, 1998.

EATON, Kent. Parliamentarism versus Presidentialism in the Policy Arena. Comparative Politics, 32 (3), p. 355-376, 2000.

JONES, Mark P. Electoral Laws and the Survival of Presidential Democracies. Notre Dame: University of Notre Dame Press, 1995.

LINZ, Juan J. Presidential or Parliamentary Democracy: Does it Make a Difference?. In: LINZ, J.J. e VALENZUELA, A. (ed.). The Failure of Presidential Democracy. The Case of Latin America.

Baltimore: The Johns Hopkins University Press, p. 3-90, 1994. 
MAINWARING, Scott. Presidentialism, Multipartism, and Democracy - the Difficult Combination. Comparative Political Studies, 26 (2), p. 198-228, 1993.

$\overline{\text { p.101-114, }} 1999$.

The Surprising Resilience of Elected Governments. Journal of Democracy, 10 (3),

MAINWARING, Scott; BRINKS, Daniel e PÉREZ-LIÑÁN, Aníbal. Classifying political regimes in Latin America, 1945-1999. Studies in Comparative International Development, 36 (1), p. 37-65, 2001.

MAINWARING, S. e SHUGART, M. S. Conclusion: Presidentialism and the Party System. In: MAINWARING, S. e SHUGART, M. S. (eds.). Presidentialism and Democracy in Latin America. Cambridge: Cambridge University Press, p. 394-439, 1997.

PÉREZ-LIÑÁN, Aníbal. Pugna de Poderes y Crisis de Gobernabilidad: ¿Hacia un Nuevo Presidencialismo? Latin American Research Review , 38 (3), 2003, no prelo.

PRZEWORSKI, Adam; ALVAREZ, Michael E.; CHEIBUB, José Antonio e LIMONGI, Fernando. Democracy and Development. Political Institutions and Well-Being in the World, 1950-1990. Cambridge: Cambridge University Press, 2000.

RAGIN, Charles C. Fuzzy-Set Social Science. Chicago: The University of Chicago Press, 2000.

RIGGS, Fred W. The Survival of Presidentialism in America: Para-Constitutional Practices. International Political Science Review, 9 (4), p. 247-278, 1988.

RUSTOW, Dankwart A. Transitions to Democracy: Toward a Dynamic Model. Comparative Politics, 2 (3), p. 337-63, 1970.

SEAWRIGHT, Jason. Testing for Necessary and/or Sufficient Causation: Which Cases are Relevant? Political Analysis, 10 (2), p. 178-193, 2002.

SHUGART, Matthew S. e CAREY, John M. Presidents and Assemblies. Constitutional Design and Electoral Dynamics. Cambridge: Cambridge University Press, 1992.

STEIN, Ernesto; TALVI, Ernesto e GRISANTI, Alejandro. Institutional Arrangements and Fiscal Performance: The Latin American Experience. In: POTERBA, J. M. e HAGEN, J. V. (eds.) Fiscal Institutions and Fiscal Performance. Chicago: The University of Chicago Press, p. 103-133, 1999.

TSEBELIS, George. Decision Making in Political Systems: Veto Players in Presidentialism, Parliamentarism, Multicameralism, and Multipartyism. British Journal of Political Science, 25 (3), p.289-325, 1995. 
TSEBELIS, George e MONEY, Jeannette. Bicameralism. Cambridge: Cambridge University Press, 1997.

VALENZUELA, Arturo. Party Politics and the Crisis of Presidentialism in Chile: A Proposal for a Parliamentary Form of Government. In: The Failure of Presidential Democracy, Vol. 2, p. 91-150. The Press, 1994.

WEYLAND, Kurt. The Politics of Market Reform in Fragile Democracies: Argentina, Brazil, Peru, and Venezuela. Princeton: Princeton University Press, 2002.

THE WORLD BANK. World Development Report 2002. Building Institutions for Markets. Oxford: Oxford University Press, 2002. Aprovado para publicação em janeiro de 2004.

Tradução do original em inglês por Pedro Maia Soares. 